TECHNICAL REPORT

September 1, 1991 through November 30, 1991

Project Title:

Principal Investigator:

Project Monitor:

\section{Dewatering Studies of Fine Clean Coal DE-FG22-9irc91334}

Dr. B.K. Parekh, University of Kentucky Center for Applied Energy Research

Dr. Dan Banerjee, CRSC

\title{
ABSTRACT
}

Physical cleaning of ultra-fine coal using an advanced froth flotation technique provides a low ash product, however, the amount of water associated with clean coal is high. Economic removal of water from the froth will be important for commercial applicability of advanced froth flotation processes. The main objective of the present research program is to study and understand the dewatering characteristics of ultra-fine clean coal and to develop the process parameters to effectively reduce the moisture to less than 20 percent in the clean coal product. The research approach under investigation utilizes synergistic effects of metal ions and surfactant to lower the moisture of clean coal using a conventional vacuum dewatering technique. During the last year's effort, it was reported that a combination of metal ion and surfactant provided a 22 percent moisture filter cake.

During this contract period, adsorption studies of cationic and non-ionic surfactants onto clean coai were conducted. Monolayer coverage for cationic surfactant CPC occurred at an equilibrium concentration of $30 \mathrm{mg} / \mathrm{l}$ while for nonionic Triton X-114, monolayer coverage occurred at $1 \mathrm{mg} / \mathrm{l}$ anci formation of a second layer occurred at $10 \mathrm{mg} / \mathrm{l}$.

FTIR analyses showed that copper ions adsorb onto the coal surface by means of both electrostatic attraction and hydrogen bonding. Adsorption of anionic surfactant appeared to take place only after the adsorption of $\mathrm{Cu}^{+2}$ ions. Continuous dewatering tests were initiated using a laboratory vacuium drum, filter. Tests were completed to determine the operating parameters required to produce a $0.5 \mathrm{~cm}$ thick cake under continuous operation for comparison to results obtained in previously reported batch filtration testing. Results showed that moistures obtained in batch filtration testing can be reproduced in coritinuous filtration.

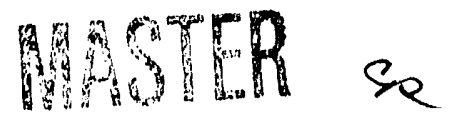

DISTARIONTION OF THIS DOOUMAENT IS UNLIMITED

This project is funded by the U. S. Department of Energy (PETC) and by the Illinots Department of Energy and Natural Resources as part of their costshared program. 


\section{EXECUTIVE SUMMARY}

Recovery of fine clean coal from waste streams offers an attractive source of lowash, low-pyritic sulfur clean coal. In the fine state, most of the mineral matter is liberated and could be effectively removed by the newly developed advanced column flotation technology. These fine coal cleaning techniques will be particularly applicable to the Illinois high ash, high pyrite sulfur coals, where ultrafine grinding is necessary to liberate the mineral matter. However, if the recovered fine clean coal cannot be dewatered to a low (less than 20 percent) moisture level, then acceptance of these newly developed techniques by the coal industry is unlikely.

This is a two-year research project. In last year's research efforts, it was discovered that metal ion or surfactant alone does not significantly lower moisture in the filter cake. However, combination of metal ion and surfactant provided a filter cake containing about 22 percent moisture. Studies are being continued to optimize the process conditions.

This quarter, adsorption studies of cationic (Cetyl Pyridinium Chloride) and nonionic (Octyl Phenoxy Polyethoxy Ethanol) surfactants onto the clean coal were conducted. Cationic surfactant adsorption onto coal showed the formation of a monolayer at an equilibrium concentration of $50 \mathrm{mg} / \mathrm{l}$ with an adsorption density of $20 \mathrm{mg}$ surfactant per gram of dry coal. The non-ionic surfactant showed a higher affinity for the coal surface with monolayer coverage occurring at an equilibrium concentration of only $1 \mathrm{mg}, \mathrm{i}$ with an adsorption density similar to that of the cationic surfactant. Formation of a second layer of non-ionic surfactant was observed at an equilibrium concentration of $10 \mathrm{mg} / \mathrm{l}$.

FTIR spectroscopy studies were initiated to investigate the mechanism of adsorption of metal ions and surfactants onto the coal surface. It was determined that copper ions adsorb by means of both hydrogen bonding and electrostatic attraction while the anionic surfactant adsorption occurred only after the adsorption of copper ions.

Continuous dewatering tests were also conducted using a rotary vacuum drum filter. Operating parameters such as drum rotation speed and cake formation time were investigated to provide a cake thickness similar to that used in batch filtration testing. Results indicate that the moisture obtained in batch filtration testing could be reproduced in continuous filtration.

Studies will be conducted using the AC Electro-coagulator to provide the metal ions and then serri-continuous filtration studies will be conducted. It is also planned to conduct additional morphology studies of the fil'cer cake. 


\section{OBJECTIVES}

The main objective of the proposed program is to study and understand the dewatering characteristics of fine clean coal obtained using the advanced column flotation technique from the Kerr-McGee Galatia Preparation Plant's fine refuse stream. The ultimate objective is to develop the process criteria to obtain a dewatered clean coal product containing less than 20 percent moisture utilizing conventional dewatering equipment.

The above-stated objectives will be achieved using five (5) different tasks. Task 1 involving acquisition and characterization of the fine clean coal product obtained from the 'Ken.Flote' column has been completed. Task 2 on the investigation of surface chemical properties of the coal before and after flotation, with and without the presence of various surfactants and metal ions has been completed. Task 3 on laboratory dewatering studies of the clean coal product utilizing information gathered in Task 2 is in progress. Task 4 involving the utilization of the novel AC Electro-Coagulation technique will be conducted in the later part of the program. Task 5 on continuous dewatering tests using a laboratory vacuum drum filter is in progress. Continuation of Task 5 will utilize optimum process conditions identified in Tasks 2, 3 and 4.

\section{INTRODUCTION AND BACKGROUND}

Most of the coal presently used by the utility industry is cleaned at preparation plants employing wet processes. Water, while being the mainstay of coal washing, is also one of the least desirable components in the final product. The problem becomes severe as the coal particle size decreases. Most of the advanced physical or chemical coal cleaning processes require ultra-fine grinding of coal for liberation of impurities for their removal to produce an ultraclean coal product. The clean coal product so obtained requires extensive dewatering before it can be used. Currently available dewatering techniques are inefficient for dewatering of ultra-fine (minus 325 mesh) coal. The coal industry in the U.S. has expressed serious concern about utilizing novel advanced cleaning process, if an efficient and economical dewatering process is not available. Thus, the present research program presents a novel approach for the urgent problem which needs to be solved in a short period of time.

The research project utilizes the basic surface-colloid chemistry principle of lowering the zeta potential of coal particles through adsorption of surfactants and metal ions. Parekh" has reported that using metal ions, coagulation of ultra-fine

"Parekh, B.K., 1979, "Role of Hydrolyzed Metal lons in Charge Reversal and Coagulation Phenomena," Ph.D. thesis, The Pennsylvania State University. 
particles could be achieved effectively at the zero-point of charge of the metal ion/solid system. Usually, three charge reversal points (or points-of-zero charge) are observed for each metal ion/solid system (Figure 1). The last charge reversal point (CR3) was found to be the most effective for coagulation of particles. The zero-point of charge could also be achieved using only the surfactants. The research program will utilize the synergistic effect of metal ion, surfactant, and $\mathrm{pH}$ in a single stage to improve the dewatering characteristics of fine coal utilizing a conventional vacuum dewatering technique.

It was reported by the CAER that metal ions or surfactant alone were not able to significantly reduce the moisture in the filter cake, however, a combination of the two (ie. metal ions and surfactant) wias effective in providing a filter cake containing about 22 percent moisture. During this quarter additional studies related to adsorption of metal ion and surfactant combination, their sequence of addition in coal and their mode of adsorption were conducted.

This report describes the experimental results, conclusions and recommendations for the period September 1, 1991 through November 30, 1991.

\section{EXPERIMENTAL PROCEDURES}

The adsorption of cationic and non-ionic surfactants onto coal was studied using surface tension measurements obtained with a Fisher Surface Tensiometer Model 20. Solutions of varying surfactant concentrations were prepared in distilled water and their surface tensions were measured. By doing so, the relationship between surface tension and surfactant concentration was determined so that an unknown surfactant concentration could be determined by measurement of the solution surface tension. To determine the amount of surfactant adsorbed on the coal surface, $1.0 \mathrm{~g}$ of coal was conditioned with a known amount of surfactant for 15 minutes. During the conditioning time, $\mathrm{pH}$ was monitored and remained constant. The conditioned slurry was then filtered through Millipore filter paper and the surface tension of the clear filtrate was measured, from which the surfactant concentration was determined. The difference between the initial surfactant concentration and the filtrate surfactant concentration was the amount of surfactant adsorbed.

For order of addition experiments, a solution of metal ions or surfactant was added to the slurry and conditioned at constant $\mathrm{pH}$ for 5 minutes, after which the appropriate solution was added and conditioned for an additional 5 minutes again at constant $\mathrm{pH}$. The order of addition of metal ions and surfactant was varied to determine what effect this would have, if any, of filtration performance. 


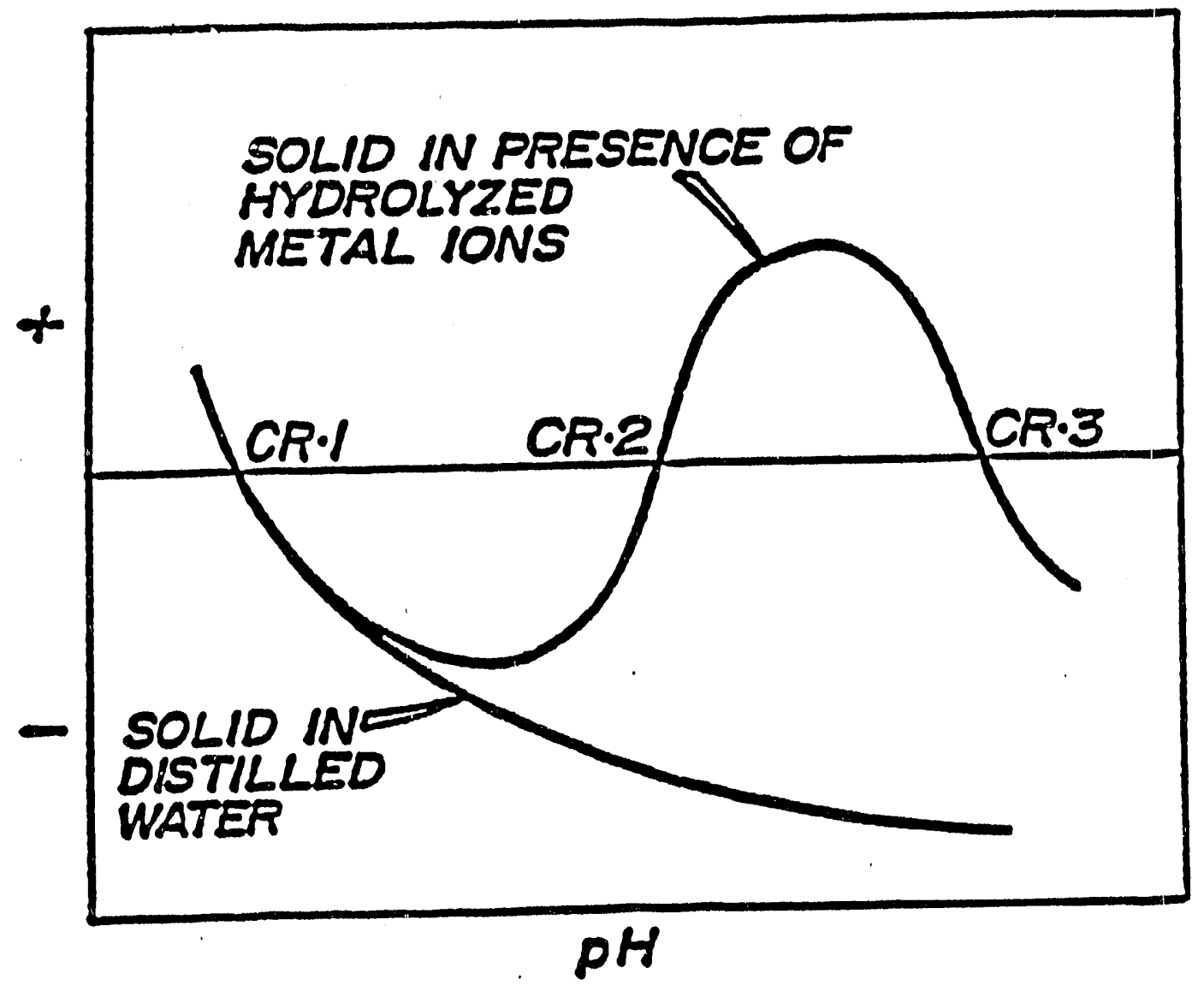

Figure 1. Charge Reversal of Solid with and without the Presence of Metal lons 
Continuous filtration testing was conducted using a WesTech Engineering 6-inch diameter by 3 -inch wide vacuum drum filter to determine if results obtained using batch filter leaf tests could be reproduced on a continuous filter. The filter tub was fed continuously with a peristaltic pump and the tub overflow returned to the feed sump to ensure a constant tub level for cake formation. The drum was rotated at the desired speed so that a uniform cake was formed, and the drying cycle time varied before the dry cake was removed by an advancing knife blade.

Fourier Transform Infrared (FTIR) spectroscopic measurements of the coal surface were made on a Nicolet 20 SXC FTIR spectrometer equipped with TGS detector. Samples were prepared by mixing one gram of coal with $10^{-4} \mathrm{M} \mathrm{Cu}^{+2}$ solution (and/or $1.6 \mathrm{Kg} /$ ton surfactant), then filtering the coal and washing five times with distilled water before drying the sample in a vacuum oven at $70^{\circ} \mathrm{C}$ for 24 hours. Transmission spectra were obtained in a $\mathrm{KBr}$ matrix prepared by mixing an accurately weighed sample (about $0.7 \%$ by weight) with $\mathrm{KBr}$ in a WigL-Big mill for five minutes. A portion of the mixture $(50 \mathrm{mg})$ was pressed into a 5 $\mathrm{mm}$ diameter disc. Primary spectra of the samples were obtained from 128 scans with a normal resolution of $4 \mathrm{~cm}^{-1}$ in the mid-IR range of $4000 \mathrm{~cm}^{-1}-400$ $\mathrm{cm}^{-1}$.

\section{RESULTS AND DISCUSSION}

During this quarter the results of the dewatering studies are reported under four different categories.

\section{Adsorption Studies:}

To determine the optimum amount of metal lons needed to form a monolayer on the coal surface, adsorption studies were conducted using the procedure described earlier. Initially, studies were conducted to determine if the surface tension technique would be suitable to determine the residual amount of surfactant. Figures 2 and 3 show the surface tension versus concentration plots for the cationic surfactant cetyl pyridinium chloride (CPC) and the nonionic octyl phenoxy polyethexy ethanol (Triton X-114) surfactants respectively. As the CPC concentration was increased form 0.1 to $250 \mathrm{ppm}$, the surface tension of the solution was reduced from 60 to 40 dynes/cm (Figure 2). At higher concentration, no additional reduction in surface tension was observed, this indicates that the Critical Micelle Concentration (CMC) of CPC is $250 \mathrm{ppm}$ which is close to the reported value of $246.6 \mathrm{ppm}$. For the Triton X-114 the CMC was at $130 \mathrm{ppm}$.

Adsorption isotherms were determined for cationic (CPC) and nonionic (Triton X114) surfactants. The adsorption isotherms obtained for CPC and Triton X-114 are shown in Figure 4. For CPC, monolayer coverage occurred at an equilibrium 


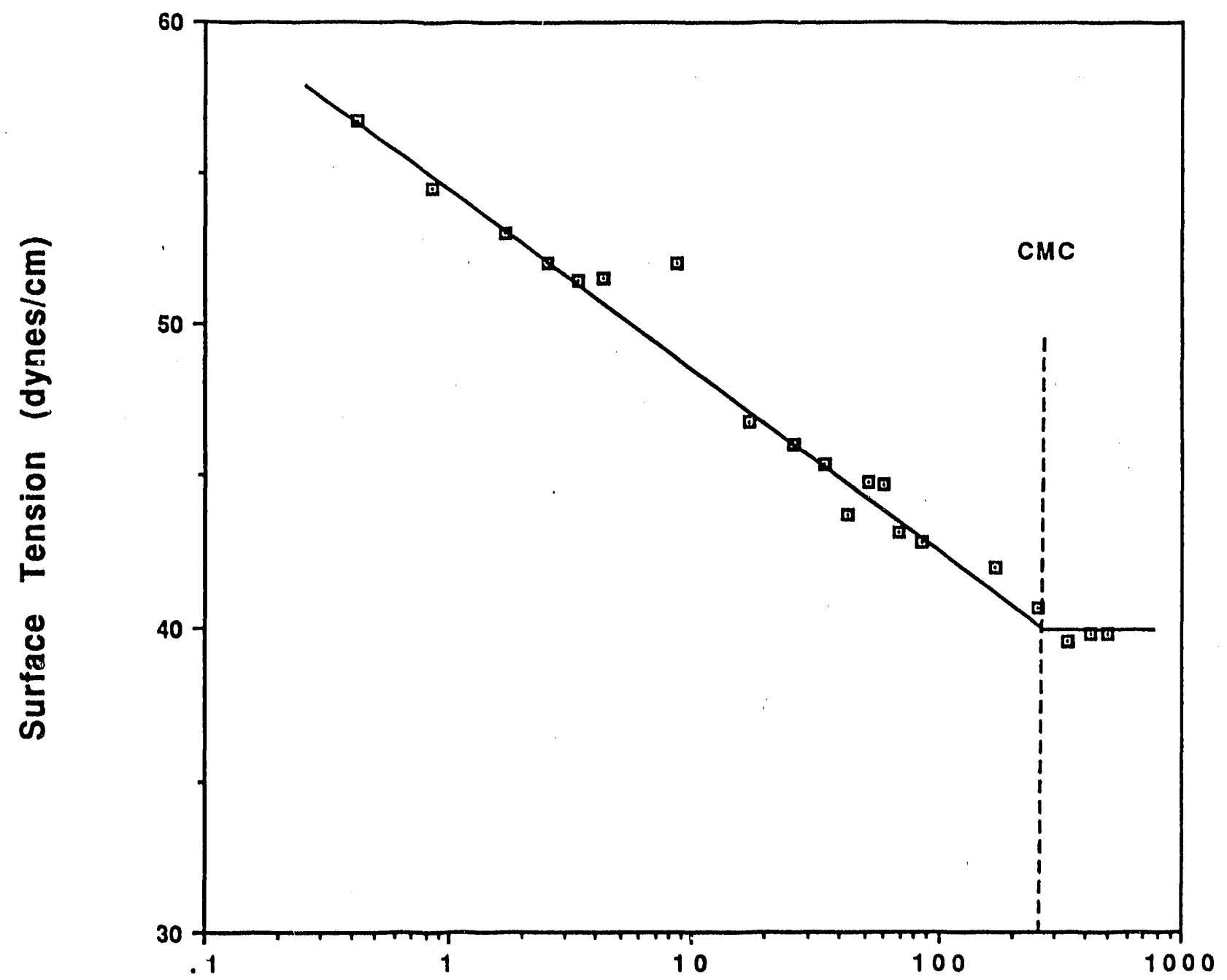

$\mathrm{CPCl}$ Concentration (ppm)

Figure 2. Surface Tension Behavior of Cetyl Pyridinium Chloride (Cationic Surfactant) at Different Concentrations. 


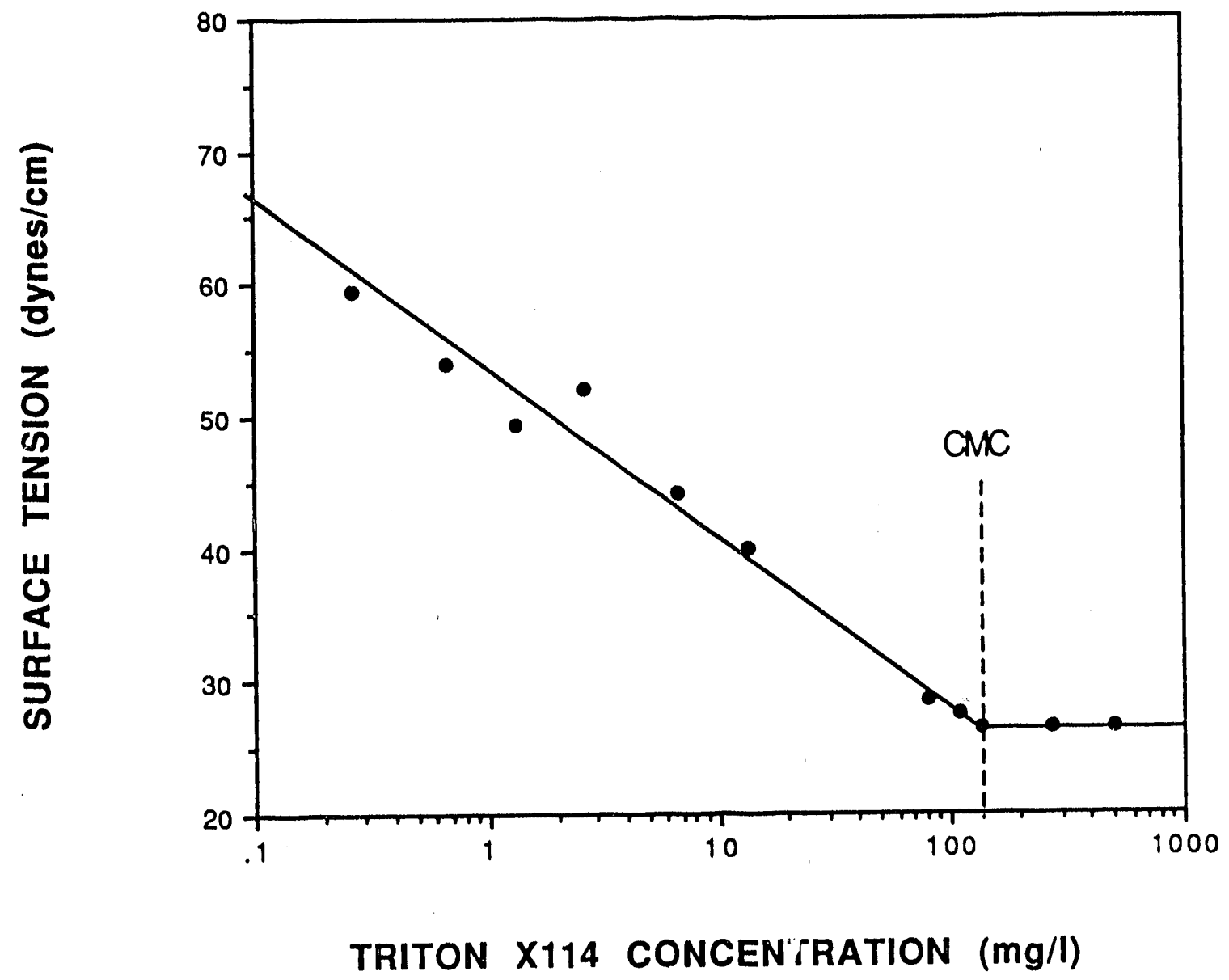

Figure 3. Surface Tension Behavior of Triton X-114 (Ocryl Phenoxy Polyethoxy Ethanol-Non-lonic Surfactant) at Different Concentrations. 


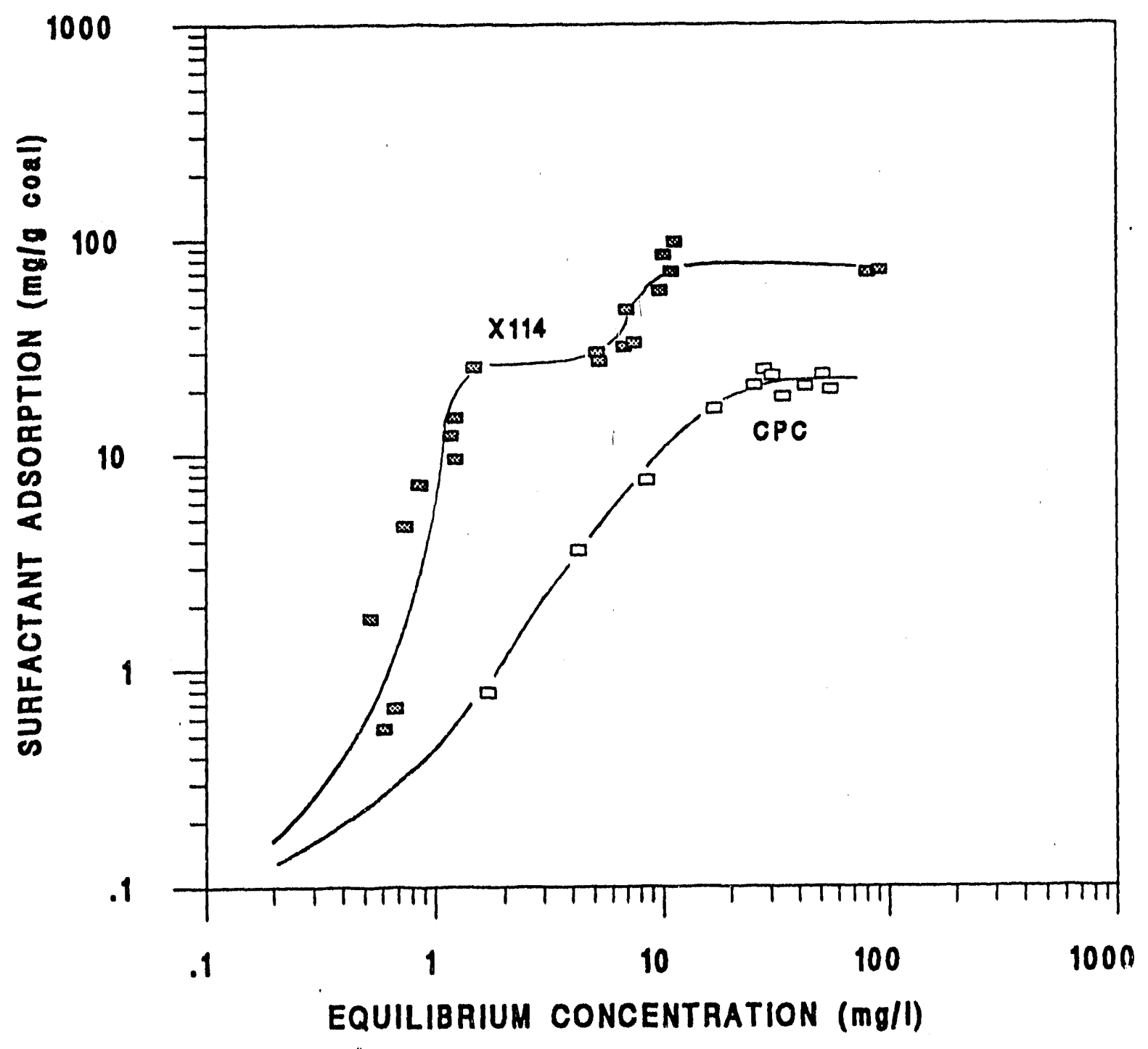

Figure 4. Adsorption Isotherms for Cetyl Pyridinium Chloride (CPC) and Octyl Phenoxy Polyethoxy Ethanol (Triton X-114) on Galatia Fine Clean Coal at Ambient Temperature. 
concentration of approximately $30 \mathrm{mg} / \mathrm{l}$; the shape of the isotherm in the lower concentration range suggests a slight affinity for the coal surface, characteristic of weak, physical adsorption. Triton X-114 showed much stronger affinity for the coal surface at low equilibrium concentration with monlayer formation at $1.0 \mathrm{mg} / \mathrm{l}$. At higher equilibrium concentration, the formation of a second layer occurred and was completed at $10 \mathrm{mg} / \mathrm{l}$. Formation of multilayers is not unusual for surfactants and is dependent on the interaction of the polar and non-polar ends of the surfactant molecule and their orientation during adsorption.

\section{Order of Addition of Reagents:}

Baseline cake moisture values with metal lons alone are given in Table 1. Reagent concentrations were selected from previous studies, where low cake moistures were observed. No significant reduction in cake moisture was noticed except with titanium lons. Cake moisture behavior with anionic, non-ionic and cationic surfactants alone at different dosages is presented in Figures 5-7.

Anionic and cationic surfactants did not significantly lower moisture even at high dosages of 1.0 and $1.5 \mathrm{Kg} / \mathrm{ton}$, respectively. In the case of non-ionic surfactant, considerable reduction of moisture to about $20 \%$ was noticed but at a high dosage of $1.5 \mathrm{Kg} / \mathrm{ton}$.

After these baseline studies, experiments were conducted by adding both surfactant and metal ion and also changing their order of addition. Reagent dosages, their order of addition and cake moisture values are summarized in Table 2. Overall change in moisture reduction due to change in order of addition of reagents is only within $1 \%$ in most cases. When cetyl pynidinium chloride was used with copper and aluminum lons, the change is slightly above $1 \%(1.58 \%$ and $1.2 \%$, respectively) but not significantly different. Sodium 2 -Ethylhexyl Sulfate (anionic surfactant) $(0.53 \mathrm{Kg} /$ ton) in combination with copper ions $(0.23$ $\mathrm{Kg} /$ ton) gave low moisture values of about $23 \%$. Octyl Phenoxy Polyethoxy Ethanol (non-ionic surfactant) gave low cake moistures even without any addition of metal ions, but at a high dosage ui $1.5 \mathrm{Kg} / \mathrm{ton}$. In the case of Cetyl Pyridinium Chloride (Cationic Surfactant), cake moisture reduction did not improve by changing order of addition of reagents.

Fourier Transform-Infrared (FTIR) Spectroscopic Analysis of Coal Surface:

FTIR measurements were conducted to confirm the adsorption of metal ions and/or surfactants after filtration and to identify possible adsorption mechanisms. FTIR spectrum of the coal sample tested with copper ions and anionic surfactant (Sodium 2-Ethylhexyl Sulfate) separately and together are presented in Figure 8. After $\mathrm{Cu}^{+2}$ adsorption on the coal surface, the hydroxyl $(-\mathrm{OH})$ stretching at 3400 


\section{TABLE 1}

\section{Baseline Data: Effect of Metal Ions Alone on Dewatering}

Slurry : $150 \mathrm{~g}, 20 \%$ solids

Reagent Concentration

Blank

$\mathrm{Cu}$ only (from $\mathrm{CuCl}_{2} \cdot 2 \mathrm{H}_{2} \mathrm{O}$ ) $0.23 \mathrm{~kg} / \mathrm{t}$

Al only (from $\mathrm{AlCl}_{3}$ )

$0.15 \mathrm{~kg} / \mathrm{t}$

$\mathrm{Ti}$ only (from $\mathrm{TiCl}_{4}$ )

$0.0067 \mathrm{~kg} / \mathrm{t}$
Cake Moisture. \%

26.8

26.6

26.02

24.56 
TABLE 2

\section{Effect of Order of Addition of Reagents on Dewatering}

Slurry : $150 \mathrm{~g}, 20 \%$ solids; $\mathrm{pH}: 7.6$

\begin{tabular}{|c|c|c|c|c|c|}
\hline Systern & $\begin{array}{l}\text { Percent } \\
\text { Moisture }\end{array}$ & System & $\begin{array}{l}\text { Percent } \\
\text { Moisture }\end{array}$ & System & $\begin{array}{l}\text { Percent } \\
\text { Moisture }\end{array}$ \\
\hline $\begin{array}{l}\text { S2ES/Cu } \\
0.53 / 0.23\end{array}$ & 22.98 & $\begin{array}{l}\text { OPPE/Cu } \\
1.5 / 0.23\end{array}$ & 20.59 & $\begin{array}{l}\mathrm{CPC} / \mathrm{Cu} \\
0.102 / 0.23\end{array}$ & 24.28 \\
\hline $\begin{array}{l}\text { Cu/S2ES } \\
0.23 / 0.53\end{array}$ & 23.93 & $\begin{array}{l}\text { CWOPPE } \\
0.23 / 1.5\end{array}$ & 21.07 & $\begin{array}{l}\text { Cw/CPC } \\
0.23 / 0.102\end{array}$ & 25.86 \\
\hline$\ldots \ldots \ldots$ & $\cdots \cdots$ & $\cdots \ldots \ldots$ & $\ldots \ldots$ & $\ldots \ldots \ldots$ & 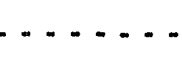 \\
\hline $\begin{array}{l}\text { S2ES/AI } \\
1.0 / 0.15\end{array}$ & 24.89 & $\begin{array}{l}\text { OPPE/AI } \\
0.54 / 0.15\end{array}$ & 23.56 & $\begin{array}{l}C P C / A I \\
0.5 / 0.15\end{array}$ & 25.93 \\
\hline $\begin{array}{l}\text { Al/S2ES } \\
0.15 / 1.0\end{array}$ & 25.36 & $\begin{array}{l}\text { AVOPPE } \\
0.15 / 0.54\end{array}$ & 24.38 & $\begin{array}{l}A V C P C \\
0.15 / 0.5\end{array}$ & 24.73 \\
\hline$\cdots \cdots$ & $\cdots \cdots$ & $\cdots$ & & 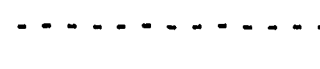 & \\
\hline $\begin{array}{l}\mathrm{S} 2 \mathrm{ES} / \mathrm{Ti} \\
0.053 / 0.0067\end{array}$ & 24.79 & $\begin{array}{l}\text { OPPE } / \mathrm{Ti} \\
0.107 / 0.0067\end{array}$ & 25.54 & $\begin{array}{l}\mathrm{CPC} / \mathrm{Ti} \\
0.0567 / 0.0067\end{array}$ & 24.56 \\
\hline $\begin{array}{l}\text { Ti/S2ES } \\
0.0067 / 0.053\end{array}$ & 25.29 & $\begin{array}{l}\text { TVOPPE } \\
0.0067 / 0.107\end{array}$ & 25.02 & $\begin{array}{l}\text { Ti/CPC } \\
0.0067 / 0.0567\end{array}$ & 24.41 \\
\hline
\end{tabular}

S2ES : Sodium 2-Ethylhexyl Sulfate (Anionic)

OPPE : Octyl Phenoxy Polyethoxy Ethanol (Non-ionic)

CPC : Cetyl Pyridinium Chloride (Cationic) 


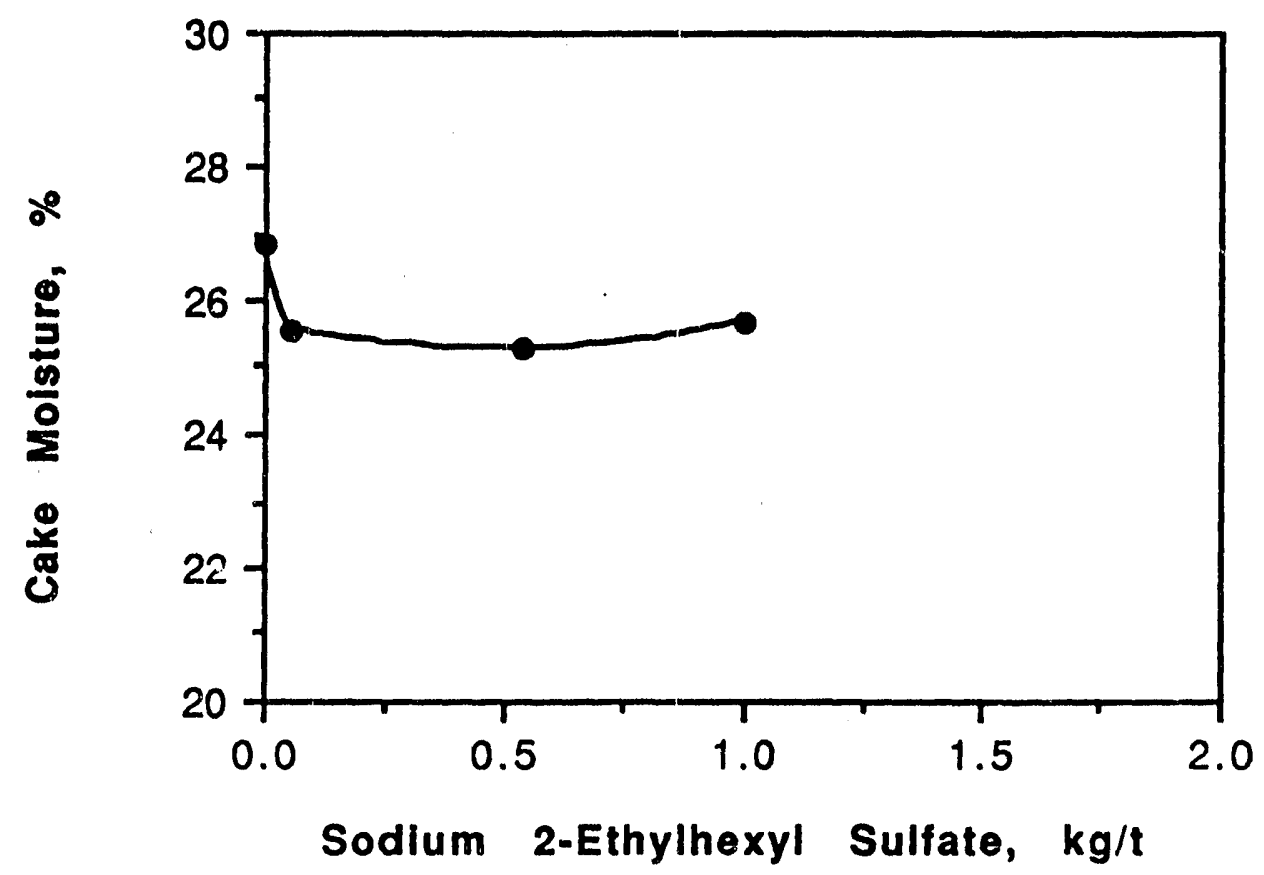

Figure 5. Effect of Sodium 2-Ethylhexyl Sulfate (Anionic Surfactant) Dosage Alone on Cake Moisture (pH:7.98). 


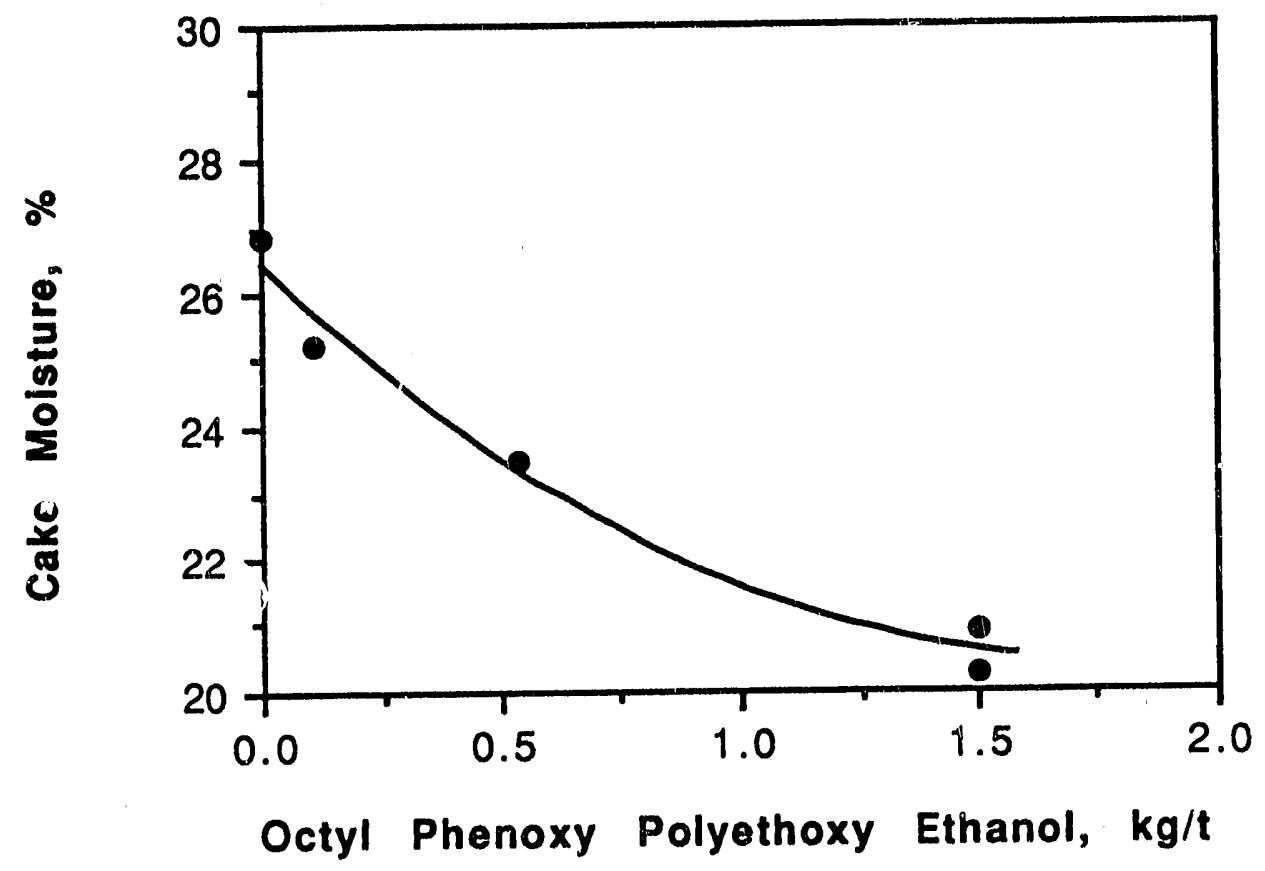

Figure 6. Effect of Octyl Phenoxy Polyethoxy Ethanol (Non-lonic Surfactant) Dosage Alone on Cake Moisture (pH:7.97). 


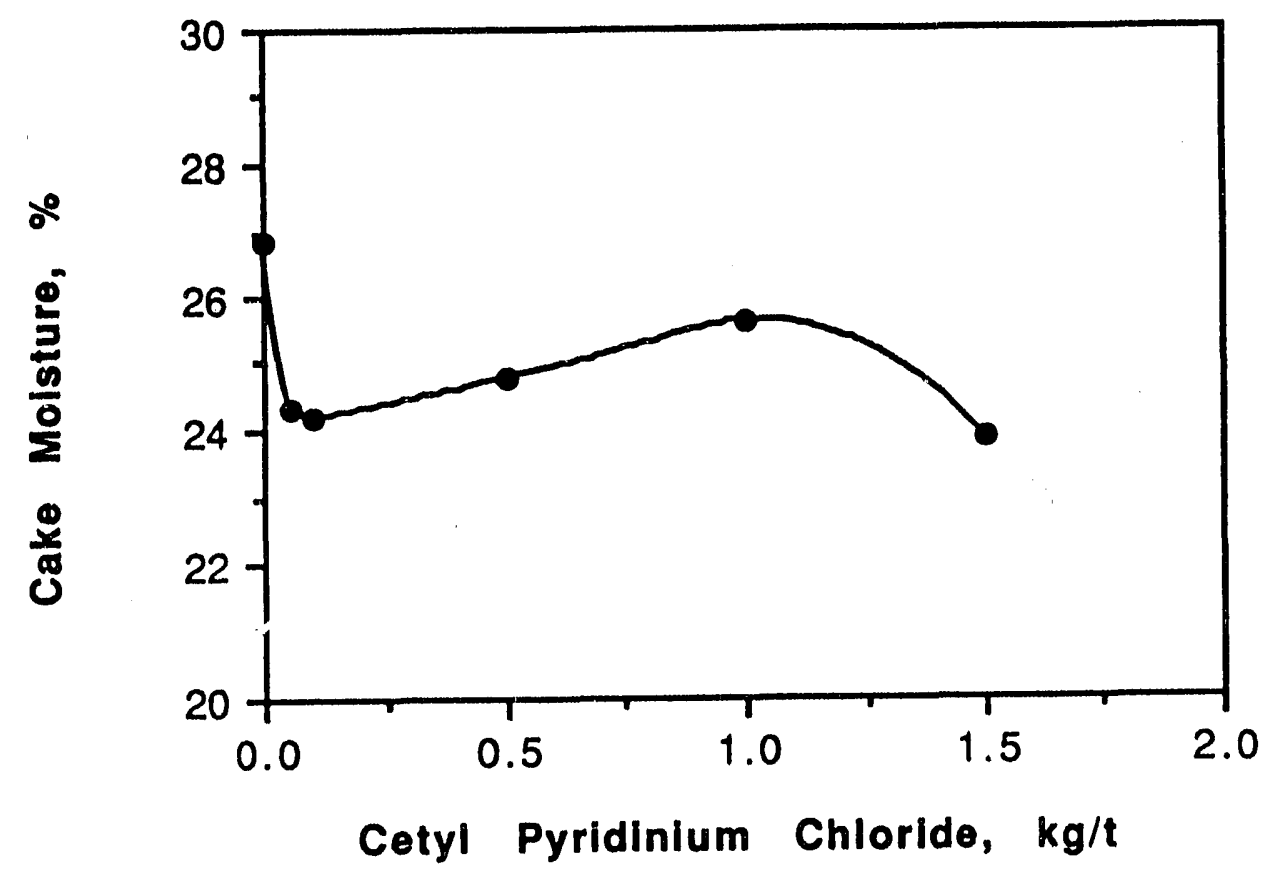

Figure 7. Effect of Cetyl Pyridiniurn Chloride (Cationic Surfactant) Dosage Alone on Cake Moisture (pH:7.87). 


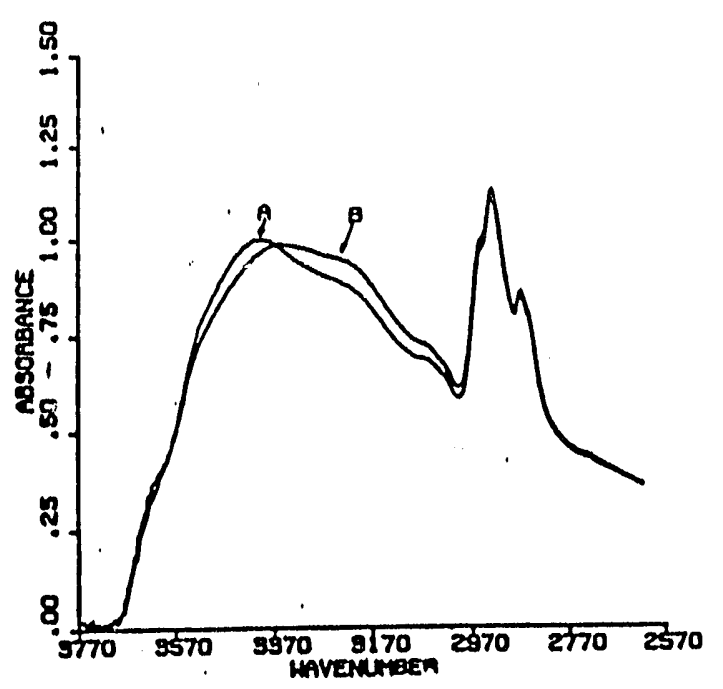

1) (A) conl sample

[B] treated with $\mathrm{Cu}^{+2}$

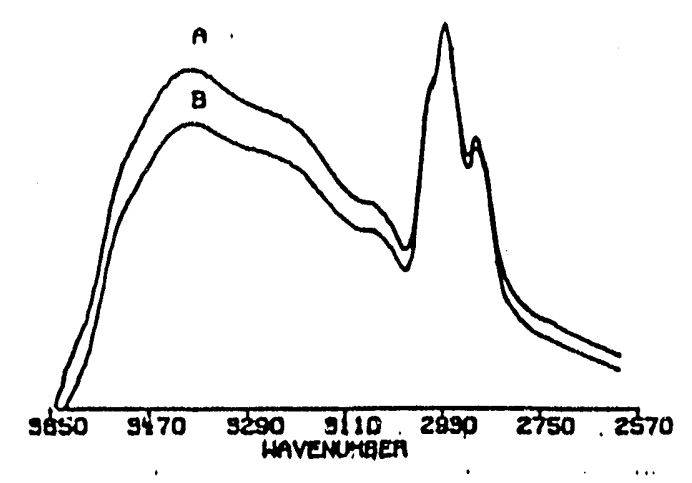

11) (A) cosl sumple

[B] treated with anienic aurfactant

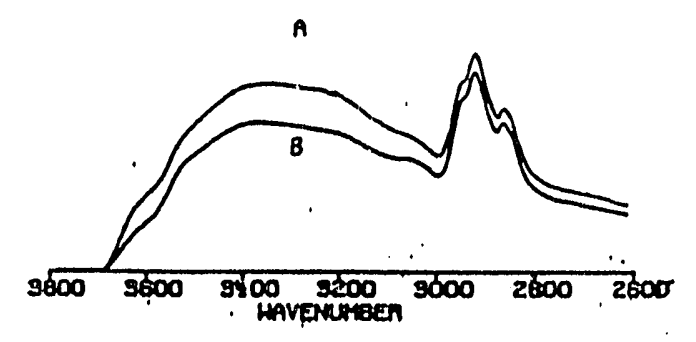

111) [A] treated with $\mathrm{Cu}^{\star 2}$

(B) treated with $\mathrm{Cu}^{+2}$ /antonic surfactant

Figure 8. FTIR Spectroscopic Analysis of Coal Surface Treated with Copper lons and Anionic Surfactant (Sodium 2-Ethylhexyl Sulfate), 
$\mathrm{cm}^{-1}$ was shifted toward lower frequency at $3353 \mathrm{~cm}^{-1}$. This change of frequency indicates that some chemical bonds were formed with hydroxyl group $(-\mathrm{OH})$ on the coal surface so as to weaken the bonding force which exists between hydrogen and oxygen inside $-\mathrm{OH}$ group. Based on the existing functional groups on the coal surface and species of $\mathrm{Cu}^{+2}$ in solution, it can be assumed that $\mathrm{Cu}(\mathrm{OH})^{+1}$ is likely to be adsorbed on the coal surface by means of hydrogen bonding formed with hydroxyl groups or carboxyl groups on the surface.

The same intensities of two spectra illustrate that $-\mathrm{CH}_{3}$ stretching peak does not change at all after $\mathrm{Cu}^{+2}$ adsorption on the surface. In other words, $\mathrm{Cu}^{+2}$ is not able to be adsorbed by aliphatic groups (hydrophobic sites) on the coal surface. In contrast, most $\mathrm{Cu}^{+2}$ was adsorbed on the hydrophilic sites such as hydroxyl or carbonyl groups through both hydrogen bonding and electrostatic attraction. It is clear that the peak frequency was not shifted after adsorption of $\mathrm{Cu}^{+2} /$ surfactant on the coal surface compared with that only treated by $\mathrm{Cu}^{+2}$. However, the decrease of peak intensity in $3400-3100 \mathrm{~cm}^{-1}$ may be due to disassociation of $\mathrm{Cu}^{+2}$ complexes formed with surfactant on the coal surface into solution.

After the coal surface was treated only by anionic surfactant, the spectra did not shift any more compared to that without any treatment. It can be seen that no peak frequency was changed except that peak intensity near $3400-3100 \mathrm{~cm}^{-1}$ (-OH stretching) was decreased. This Illustrates that anionic surfactant is very difficult to be adsorbed by the coal surface because of electrostatic repulsion. However, anionic surfactant can remove some water from the coal surface causing weak peak intensity at $3400-3100 \mathrm{~cm}^{-1}$.

\section{Continuous Filtration Testing:}

Continuous filtration tests were completed to determine the operating parameters required to produce a $0.5 \mathrm{~cm}$ thick filter cake under continuous operation for comparison to batch filtration tests reported previously. Using a 20 percent solids feed slurry and a filter tub depth of $10.0 \mathrm{~cm}$, a cake formation time of 40 seconds was required to produce a $0.5 \mathrm{~cm}$ thick cake. After formation of a uniform cake thickness, the length of the drying cycle was varied to determine the effect of drying time on cake moisture. The results are shown in Figure 9. After a total filtration of 2 minutes, the cake moisture was reduced to 32.9 percent moisture which was the same as was obtained with batch filter leaf testing. The final moisture after five minutes of filtration with the continuous drum filter was 29.1 percent versus 26.6 percent for batch leaf filtration. These results show that the moisture obtained with batch filtration can be reproduced with continuous filtration. 


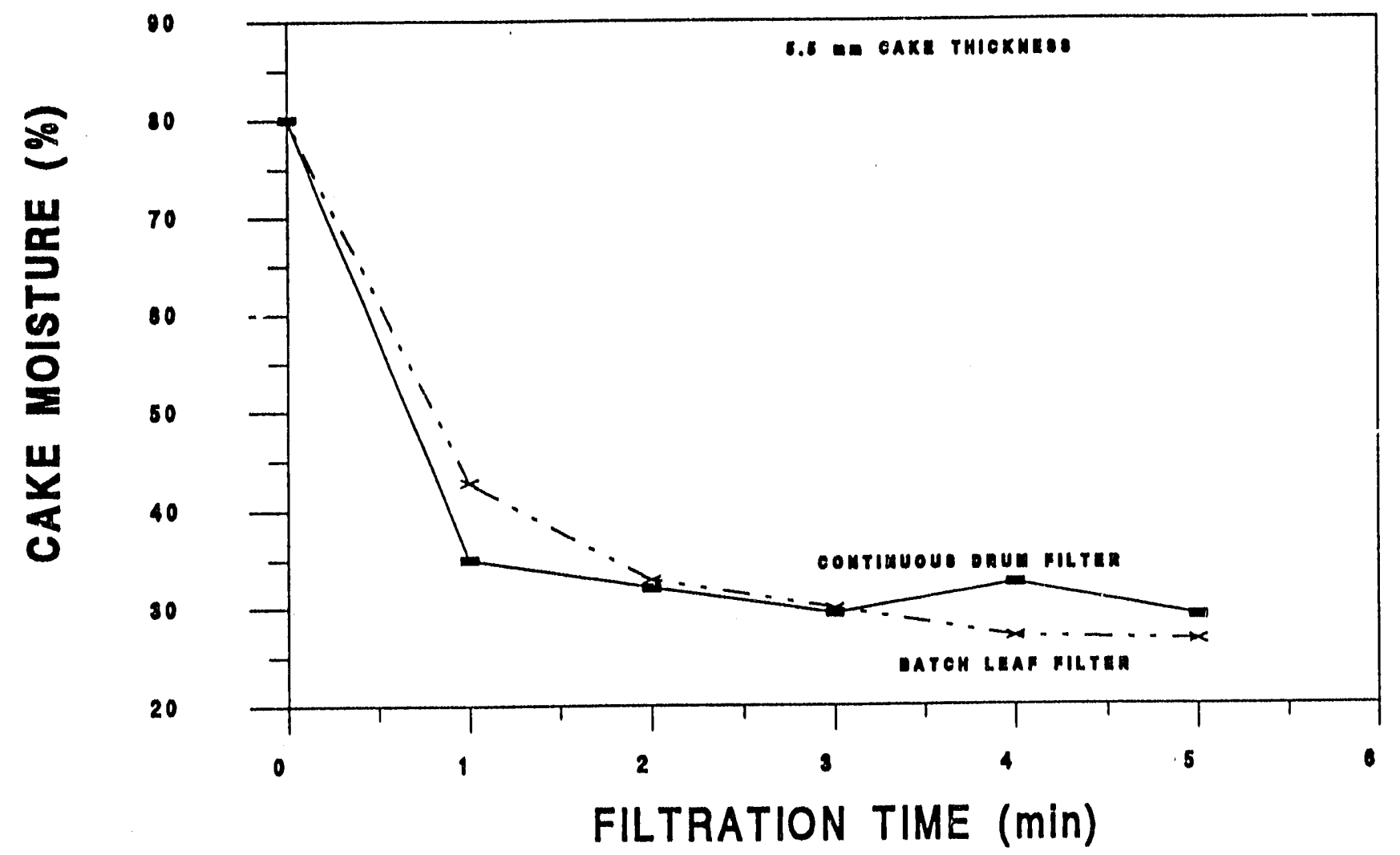

Figure 9. Comparison of Cake Moisture Variation with Filtration Time of Batch and Continuous Filters. 


\section{CONCLUSIONS AND RECOMMENDATIONS}

- Critical Micelle Concentrations (CMC) (250 and 130 ppm respectively) of Cetyl Pynidinium Chloride (CPC) and Octyl Phenoxy Polyethoxy Ethanol (Triton X114) measured in these tests are in excellent agreement with literature values (246.6 and $130 \mathrm{ppm}$ respectively).

- Monolayer coverage for CPC and Triton X-114 occurred at concentration of 30 $\mathrm{mg} / \mathrm{l}$ and $1 \mathrm{mg} / \mathrm{l}$ respectlvely. Formation of a second layer is noticed at 10 $\mathrm{mg} / \mathrm{l}$ for Triton X-114.

- Order of addition of reagents did not show any significant change in cake moisture reduction. Addition of metal ions or surfactants alone did not significantly lower cake moisture except when titanium lons or high dosages of non-ionic surfactant were used.

- Of all combinations and orders of addition, anionic surfactant $(0.53 \mathrm{Kg} / \mathrm{ton})$ wit' 7 copper lons $(0.23 \mathrm{Kg} / \mathrm{ton})$ gave lower cake moisture with relatively small dosages of reagents. Low cake moistures were also obtained with non.lonic surfactant and no metal lons, however, the surfactant dosage was high (1.5 $\mathrm{Kg} /$ ton).

- Copper can adsorb on the coal surface by means of both hydrogen bonding and electrostatic attraction. Adsorption of anionic surfactant onto coal appears to take place only after the adsorption of $\mathrm{Cu}^{+2}$ ions.

- Preliminary results from continuous dewatering tests using a laboratory vacuum drum filter indicate that the moisture obtained from batch filtration can be reproduced in continuous filtration.

\section{FUTURE WORK}

- Dewatering studies will be conducted with AC Electro-Coagulator, which will provide in-line metal lons (aluminum) to induce coagulation.

- Semi-continuous dewatering tests with vacuum drum filter will be continued utilizing the optimum amount of reagents found to be effective in dewatering of ultra-fine size clean coal.

- Correlations among coal filter cake parameters such as permeability, specific resistance, $\mathrm{pH}$ and reagent dosage will be developed from kinetic; data of filtration tests conducted earlier. 


\section{PROJECT MANAGEMENT REPORT}

Sept. 1, 1991 through Nov. 30, 1991

Project Title:

Principal Investigator:

Project Monitor:
Dewatering Studies of Fine Clean Coal

Dr. B.K. Parekh

University of Kentucky

Center for Applied Energy Research

Dr. Dan Banerjee

Center for Research on Sulfur in Coal

\section{COMMENTS}

The project is progressing on schedule. At present, we do not anticipate any problems in the tasks proposed for the research program. Due to sime accounting problems, the total money spent on the projeci came lower than projected amount.

\section{DISCLAIMER}

This report was prepared as an account of work sponsored by an agency of the United States Government. Neither the United States Government nor any agency thereof, nor any of their employees, makes any warranty, express or implied, or assumes any legal llability or responsibility for the accuracy, completeness, or usefulness of any information, apparatus, product, or process disclosed, or represents that its use would not infringe privately owned rights. Reference herein to any specific commercial product, process, or service by trade name, trademark, manufacturer, or otherwise does not necessarily constitute or imply its endorsement, recommendation, or favoring by the United States Government or any agency thereof. The views and opinions of authors expressed herein do not necessarily state or reflect those of the United States Government or any agency thereof.

This project is funded by the U. S. Department of Energy (PETC) and by the Illinols Department of Energy and Natural Resources as part of their costshared program. 

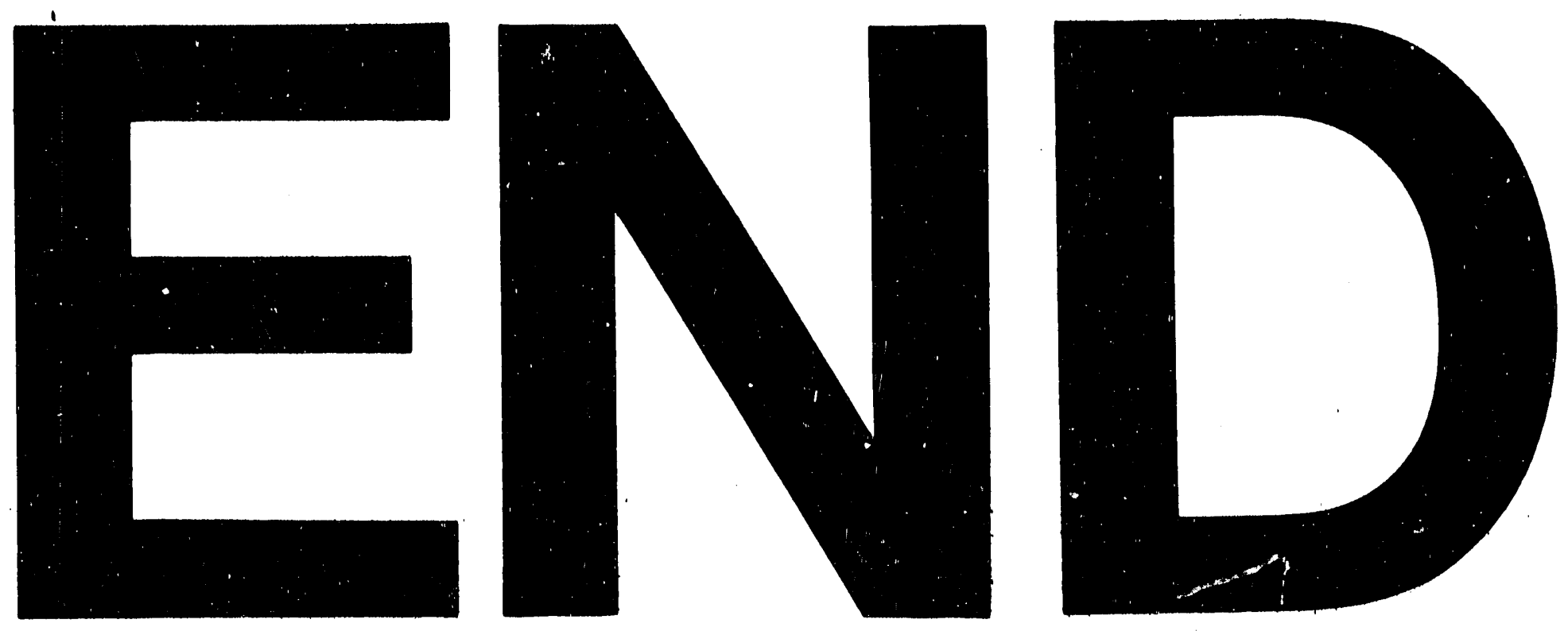

'tex
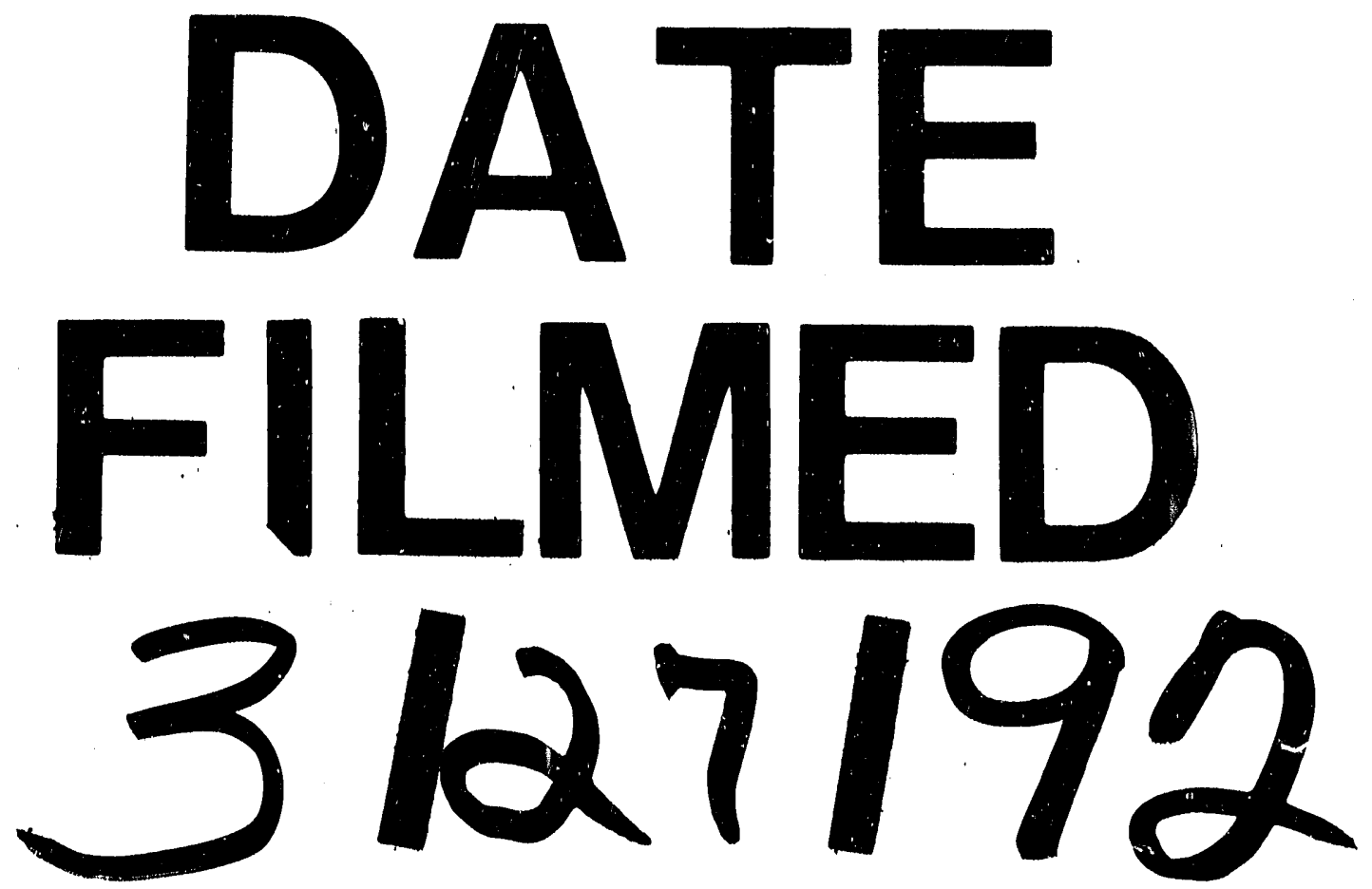

! 


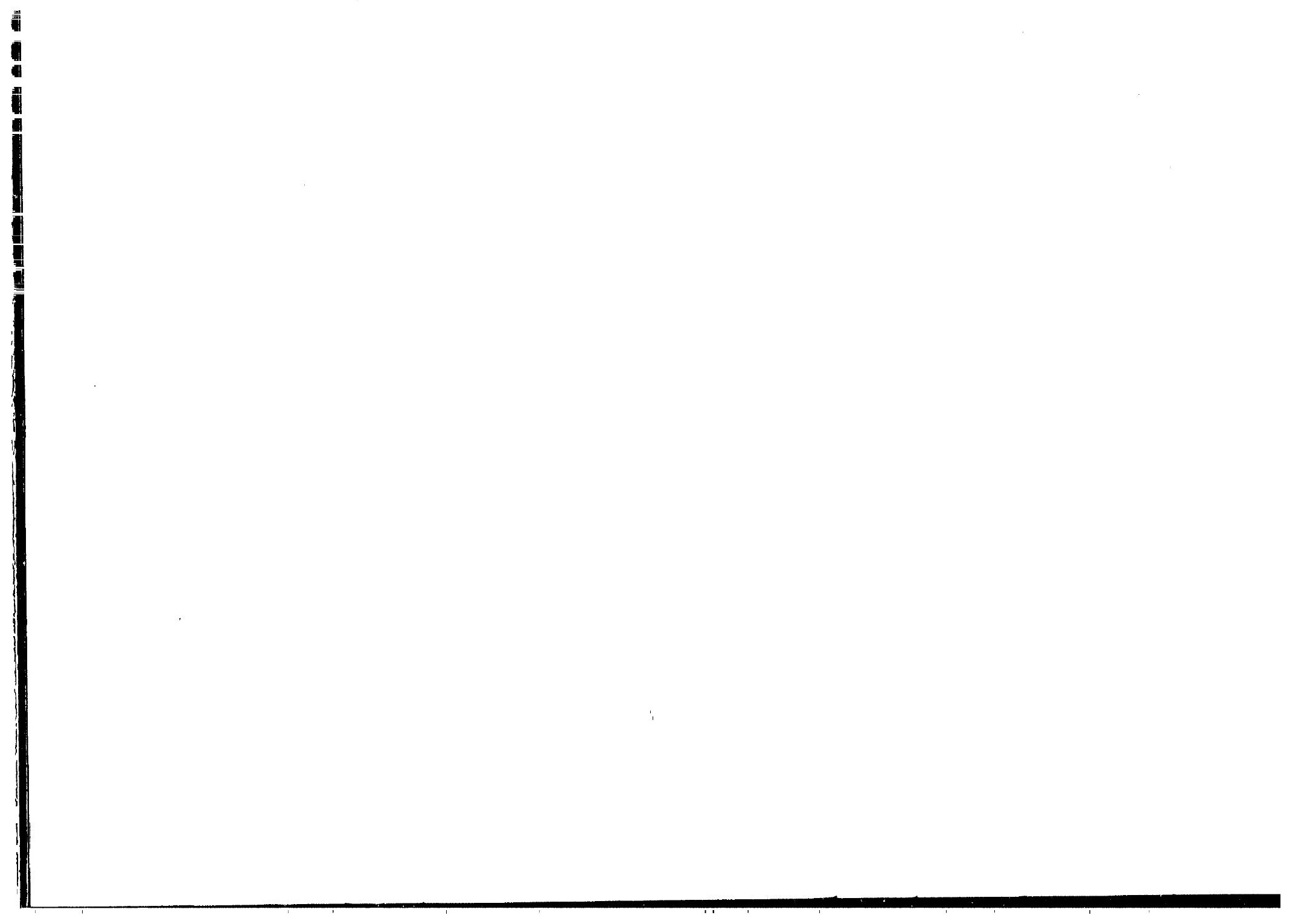

